\title{
A sistematização do conhecimento ginástica nas aulas de educação física nas escolas de referência em ensino médio do estado de Pernambuco ${ }^{1}$
}

\author{
Systematization of gymnastic knowledge in physical education classes in reference schools \\ in the middle school of the state of Pernambuco \\ La sistematización del conocimiento gimnástico en las clases de educación física en las \\ escuelas de referencia en enseñancia medio del estado de Pernambuco
}

Rafaelle de Araujo Lima e Brito ${ }^{\mathrm{a}}$ (D), Eliana Ayoub ${ }^{\mathrm{b}}$ (D), Ana Rita Lorenzinic (D), Marcelo Soares Tavares de Meloc (D)

Palavras-chave

Ginástica;

Educação Física;

Ensino médio;

Prática pedagógica.

\section{Keywords}

Gymnastics;

Physical Education;

High school;

Pedagogical practice.

Palavras-clave

Gimnasia;

Educación Física;

Escuela secundaria;

Práctica pedagógica.

\begin{abstract}
RESUMO
O estudo analisou a sistematização da Ginástica nas aulas de Educação Física, procurando refletir sobre a necessidade de existir uma sequência do ensino visando às aprendizagens dos estudantes. A investigação ocorreu a partir de uma pesquisa qualitativa, em que foram utilizados questionários, entrevistas e observações. Constatou-se que as dificuldades e problemáticas presentes no contexto escolar são diversas. Identificou-se, ainda, que mesmo diante da complexa realidade nas escolas, existe a preocupação com o ensino do conhecimento Ginástica de maneira sistematizada. Desta forma, tal preocupação tem contribuído com a formação dos estudantes das escolas investigadas, mediante as alternativas e ações criadas pelos professores para a sistematização da Ginástica.
\end{abstract}

\section{ABSTRACT}

The study analyzed the systematization of Gymnastics in Physical Education classes, seeking to reflect on the need for sequence of teaching aimed at students' learning. The investigation took place from a qualitative research, in which questionnaires, interviews and observations were used. It was found that the difficulties and problems present in the school context are diverse. It was also identified that despite the complex reality in schools, there is a concern with teaching Gymnastics knowledge in a systematic way. In this way, this concern has contributed to the training of students in the investigated schools, through the alternatives and actions created by teachers to systematize Gymnastics.

\section{RESUMEN}

El estudio analizó la sistematización de las clases de Gimnasia en Educación Física, buscando reflexionar sobre la necesidad de una secuencia de enseñanza. La investigación se realizó a partir de una investigación cualitativa, en la que se utilizaron cuestionarios, entrevistas y observaciones. Se encontró que las dificultades y los problemas presentes en el contexto escolar son diversos. También se identificó que, a pesar de la compleja realidad en las escuelas, existe la preocupación de enseñar el conocimiento de gimnasia de manera sistemática. De esta manera, esta preocupación ha contribuido a la formación de los estudiantes en las escuelas investigadas, a través de las alternativas y acciones creadas por los docentes para sistematizar la gimnasia.

\footnotetext{
a Secretaria de Educação e Esportes, Gerência Geral Metropolitana Sul. Recife, PE, Brasil.

b Universidade Estadual de Campinas, Faculdade de Educação, Departamento de Educação, Conhecimento, Linguagem e Arte. Campinas, SP, Brasil.

c Universidade de Pernambuco, Escola Superior de Educação Física. Recife, PE, Brasil.

${ }^{1}$ O presente artigo resultou de uma pesquisa que teve como órgão financiador a Coordenação de Aperfeiçoamento de Pessoal de Nível Superior - CAPES, no período de março de 2017 a agosto de 2018.
}

\footnotetext{
*Autor correspondente:

Rafaelle de Araujo Lima e Brito

E-mail: rafaelle.brito@hotmail.com
} 


\section{INTRODUÇÃO}

Nesta investigação, tomando como referência Coletivo de Autores (1992), Sacristán (2000), Almeida (2005), Lorenzini (2013), entendemos que a instituição escolar possui sua função social e a mesma tem o dever de tratar o conhecimento com os sujeitos que fazem parte da escola. Não é suficiente apenas o ensino do conhecimento aos estudantes de forma desarticulada. Esta precisa ser sistematizada, ou seja, os estudantes precisam conseguir elaborar o pensamento sobre o conhecimento aprendido, tendo o professor a responsabilidade de aprofundá-lo desde a sua origem histórico-cultural até chegar ao seu valor educativo para os estudantes, sua prática social.

Nesse processo, ressaltamos a importância de se estabelecer nexos e relações com os aspectos políticos, sociais, culturais, econômicos, dentre outros, aos quais o conhecimento está atrelado, com a preocupação de referenciar o nível de aprofundamento para cada ano de ensino até possibilitar ao estudante uma compreensão ampla e complexa dos diversos conhecimentos. Essa preocupação vai ao encontro de pensarmos num currículo que é tomado como ponto de partida para a transformação social (Sacristán, 2000), considerando a importância da construção de uma prática docente que esteja ancorada numa perspectiva educativa que se orienta para a produção coletiva de conhecimentos juntamente com os estudantes.

No caso particular do conhecimento Ginástica, segundo Almeida (2005), esta caracteriza-se como um bem cultural da humanidade, que foi historicamente edificado e socialmente ampliado. Por outro lado, Strauss (1977) afirma que a Ginástica está voltada mais para a saúde e defende que ela é um conjunto de movimentos com a finalidade de tornar o corpo harmonioso trazendo um olhar diferente em relação aos estudos de Lorenzini (2013), uma vez que a autora, ao investigar a origem e a transformação histórica da Ginástica, explicita que a mesma refere-se a um conteúdo específico de exercitação de si próprio, entrelaçado com uma forma particular de manifestação corporal, praticada sem ou com materiais, com aparelhos móveis, fixos, elásticos, leves ou pesados, em diferentes superfícies e no meio líquido, possibilitando aos aprendizes conhecer diferentes possibilidades de exercitação ao usufruir da atividade gímnica.

Por sua vez, o Coletivo de Autores (1992) traz uma concepção da Ginástica voltada para a cultura corporal, com possibilidades de ações que fundamentam significados sociais e que vão proporcionar aos estudantes, nas aulas de Educação Física Escolar, a autonomia de criarem sentindo para suas próprias exercitações ginásticas.

Desse modo, a sistematização tem potencial em construir um avanço nos processos reflexivos dos estudantes de maneira coletiva, pensando na totalidade do fenômeno estudado, desde sua origem, seus processos de transformação e o estado atual do conhecimento. Podemos considerar um aspecto indispensável nesse processo: a relação professorestudante, que vai direcionar o ensino-aprendizagem de maneira que o conhecimento seja tratado em aula, sendo vivenciado, experimentado, apreendido e desenvolvido pelos estudantes.

Coletivo de Autores (1992) toma por base o referido processo e aborda a sistematização na Educação Física, entendendo-a como um alicerce que possibilita ao estudante o processo de apropriação do conhecimento em ciclos. Para esses autores, a sistematização diz respeito a três dos quatro ciclos da escolarização. Na presente pesquisa, destacaremos o quarto ciclo de escolarização, relativo ao aprofundamento da sistematização do conhecimento, contemplando o ensino médio. Neste ciclo, entende-se que o estudante já possui a capacidade de sistematizar os conhecimentos da cultura corporal, analisando o projeto social em construção, integrando-o com sua realidade e extrapolando o conhecimento estudado no contexto escolar.

A partir do que foi exposto acima, podemos conceber que a sistematização é um conjunto de ações que visam à reflexão e à reelaboração do pensamento, passando do conhecimento sincrético, desarticulado, para um conhecimento sintético, organizado, estabelecendo nexos e relações com a realidade em que os sujeitos estão inseridos. No entanto, o conhecimento e, especificamente, a Ginástica, quando sistematizado pelo professor, necessita buscar a interação de todos os estudantes, para que assim todos possam partilhar de uma construção conjunta de conhecimentos.

Diante do exposto, indagamo-nos: como é realizada a sistematização do conhecimento Ginástica nas aulas de Educação Física dos professores das Escolas de Referência do Estado de Pernambuco? Nesse sentido, o objetivo geral da investigação consistiu em analisar a sistematização do conhecimento Ginástica nas aulas de Educação Física Escolar no Ensino Médio.

\section{MATERIAL E MÉTODOS}

O estudo se deu a partir de uma pesquisa bibliográfica e documental, utilizando a abordagem qualitativa que, segundo Sampieri et al. (2013), proporciona uma contextualização e um aprofundamento na relação com os dados, criando dessa maneira uma riqueza interpretativa. Triviños (2010) corrobora com o autor anteriormente citado quando assevera que é necessário realizar pesquisas com enfoque qualitativo pelo fato de que também é importante interpretar os dados de maneira mais ampla.

A investigação tomou por base o método hermenêutico-dialético, que trabalha com a comunicação da vida cotidiana e do senso comum, fazendo a síntese dos processos compreensivos e críticos, constituindo um caminho do pensamento que fundamentou a pesquisa a partir da comunicação como principal fonte de interpretação, buscando compreender e analisar com 
maior profundidade os dados produzidos ao longo da pesquisa (Minayo, 2010).

Desse modo, o esquema metodológico do estudo englobou: levantamento bibliográfico e análise do referencial teórico; seleção do locus da pesquisa; aplicação dos questionários aos professores; entrevistas semiestruturadas com os professores; observação participante; e análise de conteúdo dos dados construídos.

Para o aprofundamento teórico, foram estudados os documentos curriculares para o Ensino Médio do Estado de Pernambuco, dentre os quais: os Parâmetros Curriculares para a Educação Básica do Estado de Pernambuco - Parâmetros Curriculares de Educação Física - Ensino Fundamental e Médio (Pernambuco, 2013a); Parâmetros para a Educação Básica do Estado de Pernambuco - Parâmetros na sala de aula - Educação Física Ensino Fundamental e Médio (Pernambuco, 2013b); e a Proposta Curricular para o Ensino Médio Integral Linguagem e Códigos e suas Tecnologias (Pernambuco, 2012). Analisamos, igualmente, o planejamento do professor de Educação Física que foi observado no estudo. Na pesquisa de campo, realizamos a aplicação de questionários e entrevistas semiestruturadas com professores selecionados da rede estadual que ministram a disciplina de Educação Física. Ainda nesse processo, assumimos a observação participante que, segundo Silva e Pinto (2003), ocorre quando o pesquisador está diretamente envolvido com o grupo social que está estudando em seu cotidiano, dentro dos limites do próprio grupo. Desta forma, a pesquisa foi desenvolvida em diferentes fases, conforme explicitaremos a seguir.

Na primeira fase, fizemos o levantamento bibliográfico para elaboração do referencial teórico relacionado à temática da pesquisa e nessa mesma fase, analisamos os documentos curriculares do Estado de Pernambuco.

Na segunda fase da pesquisa, entramos em contato com a Secretaria de Educação e obtivemos o conhecimento da existência de 343 Escolas de Referência em Ensino Médio no Estado de Pernambuco, que foi o locus escolhido para a pesquisa, por serem escolas de tempo integral, nas quais os estudantes possuem duas aulas semanais de Educação Física. Segundo Dutra (2014), as Escolas de Referência em Ensino Médio têm as melhores estruturas físicas e financeiras e possuem o objetivo central de elevar o nível de aprendizagem dos conhecimentos dos seus estudantes ao mais alto possível, no sentido de que eles sejam protagonistas das suas próprias ações. Essas escolas buscam criar condições para uma formação que vá além dos conhecimentos formais, aspirando uma melhor qualidade na formação social de seus estudantes. Dentre as 16 Gerências Regionais de Educação (GRE), escolhemos a GRE Recife-Norte, por ser a mais próxima da Universidade de Pernambuco, considerando o tempo hábil para a realização da pesquisa.

$\mathrm{Na}$ terceira fase, iniciamos a aplicação de um questionário com os professores da disciplina de
Educação Física da GRE escolhida e que estavam dispostos a participar da pesquisa. Sendo assim, o questionário foi realizado com 9 professores, nas escolas onde atuavam, para identificar quem são esses professores e o que eles sabem sobre sistematização do conhecimento Ginástica. Além disso, explicamos aos docentes envolvidos os objetivos da pesquisa e que estavam respaldados pelo Comitê de Ética em Pesquisa. Depois desse processo, analisamos as respostas e como critério de seleção para as entrevistas, buscamos os professores que, em suas respostas, mostraram compreender a Ginástica na perspectiva da cultura corporal e a sistematização como ação que organiza os conteúdos, visando ao trato com o conhecimento. As entrevistas semiestruturadas foram realizadas com dois professores, com a utilização de um dispositivo de áudio, com perguntas que envolviam a dimensão da sistematização da Ginástica na Educação Física Escolar. Após a transcrição das entrevistas, retornamos o material transcrito para os respectivos professores para a sua aprovação e autorização a fim de que pudessem ser utilizadas na pesquisa.

A última fase se deu com a observação de aulas na Unidade de ensino Ginástica, para a qual selecionamos um professor entre os dois que participaram da entrevista, utilizando como critério de seleção: i) maior tempo de experiência na docência; ii) ministrar o conhecimento Ginástica no início do ano letivo de 2018. Deste modo, observamos as aulas nos meses de fevereiro, março e abril de 2018, acompanhando uma turma de cada ano do ensino médio, com o auxílio de uma ficha de observação. Totalizamos 34 horas-aula, sendo 12 aulas no primeiro ano, 10 aulas no segundo ano e 12 aulas no terceiro ano. As duas aulas semanais das turmas eram sequenciadas, facilitando a observação da aula e seu desenvolvimento, já que não havia interrupção.

Por fim, a análise dos dados foi realizada a partir de Bardin (2011), utilizando a técnica de análise de conteúdo categorial por temática, que consiste em um recurso de análise dos dados provenientes de mensagens escritas ou transcritas, dividindo-se em três polos cronológicos: pré-análise; exploração e análise do material; tratamento dos dados interpretados. Organizamos as informações em categorias para realizar interpretações de acordo com as análises e discussões com a literatura, considerando todas as fases da pesquisa (levantamento bibliográfico, questionários, entrevistas e observação de aulas). Nesta pesquisa, as categorias Educação Física, Ginástica e sistematização perpassam o texto de maneira articulada, pois se constituem de maneira indissociável.

\section{RESULTADOS E DISCUSSÃO}

Considerando os questionários, aproximamo-nos da realidade que está presente diariamente na prática pedagógica dos professores da rede estadual de ensino nas Escolas de Referência em Ensino Médio, mais especificamente em relação ao conteúdo Ginástica. Percebemos que apesar dessas escolas possuírem um 
diferencial, conforme explicitado por Dutra (2014), no sentido de almejar uma melhor qualidade na Educação dos estudantes, nem sempre isso é encontrado nas escolas.

Destacamos, primeiramente, a partir do que os professores afirmaram, três problemáticas: espaço físico adequado, materiais de Ginástica e interesse dos estudantes. Essas mesmas dificuldades são observadas em outros estudos da temática Ginástica na escola, como por exemplo em Costa (2016) e Schiavon e Piccolo (2007). Percebemos, ainda, que nem todas as escolas possuem quadras cobertas ou espaços cobertos para a prática da Ginástica, tendo como última opção desenvolver as atividades na própria sala de aula. No que se refere ao material, como é posto por Lorenzini (2013), a Ginástica é um conteúdo que pode ser praticado com ou sem uso de materiais. Desse modo, o professor precisa "escolher" aquela Ginástica que não precise utilizar uma quantidade grande de materiais e equipamentos, optando por práticas viáveis perante a essa falta de recursos ou mesmo criando e adequando os materiais para utilização junto com os estudantes, assim como é explicitado em Costa (2016), relatando que o professor precisa usar da sua criatividade para superar os problemas. No tocante ao interesse dos estudantes, foi exposto que o conteúdo Ginástica nem sempre é o mais aguardado ou preferido, existindo ainda algumas dificuldades para sua materialização e, desse modo, o professor em sua ação educativa necessita utilizar estratégias pedagógicas para conquistar seus estudantes a estarem motivados para a prática.

Outras problemáticas foram igualmente mencionadas: a falta de um material didático de educação física, um elemento bastante presente nas respostas dos professores; a necessidade de um conteúdo programático unificado e a fragilidade de conhecimento dos mesmos perante o conteúdo Ginástica. Tais problemáticas corroboram com o que Lara et al. (2007) afirmam sobre a grande lacuna do pensamento científico brasileiro sobre a Ginástica na Educação Física Escolar, relativa ao modo de sistematizar o conteúdo em um tempo pedagógico que, na maioria das vezes, é curto. Diante das respostas dos professores, percebemos que essas problemáticas dificultam, de fato, a sua prática pedagógica. Da mesma forma, o professor 8, em sua resposta sobre as dificuldades para sistematizar o conhecimento Ginástica, cita o "baixo conhecimento do assunto", levando-nos a considerar que ele não domina o conhecimento Ginástica, o que traz dificuldades para que ele o sistematize em suas aulas. A esse respeito, Bezerra et al. (2014) alertam que uma das grandes problemáticas que envolve esse conhecimento refere-se ao fato de os professores não saberem trabalhar pedagogicamente a Ginástica na escola.

Ainda nesse ponto relacionado às dificuldades para sistematizar o conhecimento, fazemos referência aos Parâmetros Curriculares e à Proposta para o Ensino Médio Integral, documentos produzidos para subsidiar o trabalho dos professores. Nesses documentos, a Ginástica é apresentada de maneira pedagógica e sistematizada, o que pode auxiliá-los em sua prática docente.

Quando se trata do conceito de Ginástica, os professores trazem diversos olhares, cada professor possui sua própria linha de pensamento acerca desse tema da cultura corporal e, apesar de estarem na mesma rede de ensino, seus conhecimentos, suas formações são diferentes, o que nos faz refletir que os documentos, anteriormente citados, são pouco estudados e utilizados. No entanto, no âmbito dessas respostas diversificadas, encontramos as que se aproximam do que, nesta pesquisa, colocamos como o entendimento necessário para ser inserido na escola em relação ao conhecimento Ginástica, já que se articulam com o que os documentos oficiais da rede trazem como proposta.

Em relação à sistematização, buscando dos professores o entendimento sobre essa ação, todos responderam seguindo uma lógica, como abordado pelo professor 9: "é trazer os conhecimentos desde a base inicial para a ampliação de cada conteúdo das aulas". Consideramos adequadas as respostas quanto ao que é sistematização a partir do entendimento que trazemos neste trabalho, que seria a ação de organizar os conteúdos de maneira coerente considerando cada nível de ensino, existindo uma ampliação do conhecimento com o passar dos anos.

Quando passamos para as entrevistas com os dois professores selecionados, o que percebemos foi o levantamento de algumas temáticas já desenvolvidas no questionário, que foram examinadas por meio da hermenêutica-dialética, nosso método de pesquisa, permitindo-nos aprofundar a análise das categorias, já que a mesma toma como principal base a comunicação para o exercício reflexivo.

O livro didático foi uma discussão que foi retomada pelos dois professores entrevistados e como a falta desse material específico reflete nas suas práticas docentes e até mesmo o quanto dificulta a construção da própria identidade da Educação Física na escola. A questão dos recursos materiais para as aulas do conteúdo de Ginástica também foi algo mencionado pelos professores na entrevista, pois na fala dos professores ficou claro que a falta de material é uma grande problemática para sistematizar esse conteúdo na escola. No entanto, Schiavon e Piccolo (2007) consideram que proporcionar formação continuada aos professores é mais importante do que resolver a problemática do material, considerando que o professor que domina o conhecimento pode desenvolver sua prática pedagógica mesmo com restrição de materiais.

E quando eles foram questionados sobre quais modalidades da Ginástica sistematizam, falaram que procuram sempre as modalidades que não utilizam materiais ou, quando é necessário algum material, eles são feitos de maneira adaptada. Sendo assim, refletimos o quanto é importante a seleção do saber, sua organização e, por fim, sua sistematização, pois o 
professor sabendo planejar a sua prática pedagógica conseguirá ter coerência em suas aulas e, mesmo diante das dificuldades que certamente aparecerão na realidade escolar, conseguirá encontrar caminhos para sistematizar o conhecimento, visto que o profissional já conhece o chão da sua escola e saberá o que pode ser materializado. Por isso defendemos que essa organização é importante, sobretudo quando é compartilhada coletivamente com seus pares.

Quanto a esse aspecto, foi questionado aos professores como eles planejam organizar o conteúdo Ginástica na unidade de ensino. 0 professor 8 informou, no momento da entrevista, que ainda não tinha planejado, pois estava iniciando na rede pública de ensino e teria de avaliar como seriam as adequações necessárias para esse conhecimento. Já o professor 9 trouxe de maneira bem detalhada sua organização nas aulas do conteúdo Ginástica, mostrando como organiza didaticamente os saberes diante de uma experiência já vivida na prática, a organização de seus conteúdos e como constrói sua sistematização, explicitando diferenças e avanços de um ano para o outro, aproximando-se, assim, das orientações que são propostas pelos documentos curriculares da rede, as quais trazem essa construção sistematizada em ciclos de elaboração do pensamento sobre o conhecimento.

Quanto às contribuições que a Ginástica pode trazer para a realidade dos estudantes, os professores relataram diversos pontos, indicando diferentes aspectos para os quais a Ginástica pode trazer contribuições críticas e práticas.

\begin{abstract}
O aluno aprendendo na escola, através da orientação do professor, ele tem como fazer esse link escolasociedade, por isso que eu disse que a Ginástica é importante no âmbito social. Mas também a gente não pode deixar de esquecer, embora não estejamos vivendo no momento da promoção da saúde mais, que foi na década de 40, mas a gente não pode deixar de saber que a Ginástica é muito importante para nossa saúde, para nosso corpo, como todo. (professor 8)
\end{abstract}

Dessa forma, percebemos fortemente o quanto os professores buscam incentivar os estudantes a levarem os conhecimentos estudados para fora da escola, para a vida, contribuindo, significativamente na vida dos estudantes. E quanto à Ginástica como conteúdo que traz em seu conceito a ação de exercitar o próprio corpo, acentua-se essa forte ligação com a vivência das práticas corporais para além dos muros da escola.

No que concerne à análise do planejamento do professor que foi observado (professor 9), percebemos que sua elaboração se deu a partir do plano anual elaborado pela Secretaria de Educação que é enviado aos professores da rede, que é construído considerando os documentos curriculares oficiais, os Parâmetros Curriculares e a Proposta para o Ensino Médio Integral. Desse modo, o professor, a partir de sua experiência, dialoga com o plano anual, utilizando em suas aulas apenas o que ele sabe que é possível de ser materializado em seu contexto escolar. O professor não constrói seu planejamento desprovido de reflexão. A partir de suas vivências, ele faz as modificações que julga necessárias e pertinentes por já conhecer o seu contexto de trabalho e, assim, já tem condições de ponderar sobre o que não se consegue materializar naquele ambiente, conforme mencionado anteriormente, podendo fazer a seleção, a organização e a sistematização do conhecimento (Sacristán, 2000). No que diz respeito ao planejamento de modo geral, percebemos que o professor 9 o divide por turmas, com suas habilidades, competências, conteúdos, com os procedimentos metodológicos e os procedimentos avaliativos.

Quanto às observações, percebemos que, nas primeiras aulas das turmas, o professor 9 apresentou o seu planejamento, dialogando com os estudantes sobre o que seria desenvolvido naquela unidade de ensino, qual o conteúdo, o que pretendia que fosse alcançado e aprendido naquele momento. A estruturação das aulas esteve sempre dividida em aulas práticas, que ocorriam no espaço intitulado de auditório, e em aulas teóricas na sala de aula. O procedimento inicial em todas as turmas foi a retomada da vivência da Ginástica na vida dos estudantes. Com a turma do $1^{\circ}$ ano a dificuldade era maior, mas os alunos ainda conseguiam relatar pequenas experiências vividas no contexto escolar. Com as turmas do $2^{\circ}$ e $3^{\circ}$ anos era mais fácil relembrar e reconstruir conhecimentos, pois os mesmos já tinham vivências e experimentações dos anos anteriores, uma vez que, nessa escola, o professor 9 sempre construiu o conhecimento Ginástica em todo o ensino médio, segundo o que foi relatado por ele e pelos estudantes. Analisamos que tal procedimento é importante para dar sequência à lógica do conhecimento e, principalmente, com as turmas do $1^{\circ}$ ano, formadas por alunos que estão em um ambiente novo, amigos novos e professores novos e que chegam à escola com vivências diferentes.

Assim, durante o período de observações, conseguimos visualizar os conhecimentos que foram direcionados aos estudantes, os quais também foram destacados pelo professor 9 durante a sua entrevista.

Eu trabalho muito o foco da academia e fora da academia com os alunos do primeiro ano. No caso é uma coisa crescente, não é algo que fica pertinente a essa questão da academia dentro e fora dela, mas todo o contexto, o que ela traz, qual a importância dela, essa troca também na escola, como podemos abordar isso na escola, como uma forma de ter ela como fonte de saúde e de conhecimento também. (professor $9-$ referente ao 1 음 ano)

[...] trazendo essa abordagem também quanto ao descobrimento de movimentos, então ao mesmo tempo que eu mostro a eles que existe essa parte técnica dessa atividade, eu mostro a importância 
dela enquanto o descobrimento de movimentos na ginástica, de forma mais geral. Aí eu tento trabalhar a base da ginástica do caminhar, rolar, correr, saltar; eu entro mais no segundo ano com esse conteúdo. (professor 9 - referente ao 20 ano)

[...] faço uma abordagem mais da ginástica laboral, da importância disso na escola, por eles estarem o dia todo na escola, a importância de fazer um alongamento, de ter um momento recreativo, essa importância na empresa, que vem também muito dos questionamentos deles do que eles vão querer ser enquanto profissionais. (professor 9 - referente ao 3ㅇ ano)

Durante as aulas, os estudantes se apresentavam bastante receptivos ao conhecimento. No entanto, percebemos que algumas dificuldades foram encontradas nesse percurso da unidade. Por exemplo, a quantidade de eventos e feriados que atrapalharam as aulas, diminuindo o tempo pedagógico para a sistematização do conhecimento. Outra dificuldade percebida foi a falta de material, sendo mais perceptível nas turmas dos $2^{\circ}$ anos, pois foi necessário o uso de alguns materiais específicos para a realização das atividades.

No que se refere à avaliação, os estudantes foram avaliados de maneira contínua durante toda a unidade, por meio de atividades avaliativas diversas. E, assim, foi feito o somatório das atividades realizadas e a composição da nota da unidade de ensino. Sobre isso, podemos concluir que a metodologia de ensino do professor 9 trouxe bastante dinamicidade para as aulas, mostrando que a Educação Física pode e deve estar relacionada com outras áreas do conhecimento, que pode usar a tecnologia ao seu favor e que a mesma pode ir além dos limites de uma disciplina escolar. Portanto, por meio das observações das aulas, percebemos que a metodologia do professor 9 está orientada de modo a considerar a Proposta Curricular para o Ensino Médio Integral que, segundo Dutra (2014), tem os seguintes eixos metodológicos: educação para valores; protagonismo juvenil; cultura da trabalhabilidade; avaliação interdimensional; interdisciplinaridade e contextualização. Percebemos, ainda, que o professor 9 utiliza uma metodologia que incentiva os estudantes à participação, buscando o que há de mais atual e dinâmico para suas aulas.

Durante a observação, visualizamos diferentes habilidades sendo trabalhadas ao longo das aulas ou pelo menos a tentativa de serem colocadas em prática durante a unidade de Ginástica. Sabemos que alcançar na ação educativa algo que planejamos não é uma tarefa simples. Essas habilidades que são desenvolvidas nas aulas, porém, podem ser alcançadas se houver, de fato, um planejamento que torne possível alcançar níveis mais profundos de sistematização do conhecimento.

Nessa Escola de Referência que foi campo da nossa pesquisa, por meio do planejamento do professor, da análise, das observações, conseguimos perceber que o processo de sistematização do conhecimento ocorre a partir das habilidades e capacidades direcionadas para cada ano de ensino, fazendo-nos refletir que esse processo não pode prescindir da seleção e organização dos conhecimentos, levando em consideração o tempo, o espaço, os materiais e, sobretudo, os estudantes que são os sujeitos históricos desse processo.

\section{CONCLUSÃO}

A análise dos dados desta pesquisa juntamente com a relação estabelecida com a literatura acerca do objeto de estudo, permitiu-nos compreender a sistematização do conhecimento Ginástica nas aulas de Educação Física dos professores das Escolas de Referência em Ensino Médio do Estado de Pernambuco. Verificamos que, nas aulas de Educação Física, o conhecimento Ginástica está presente e que tal conhecimento está sendo sistematizado levando-se em conta aspectos sociais e de saúde e que não está sendo tratado apenas como um instrumento.

Percebemos, por outro lado, que a literatura aqui estudada direciona a Ginástica para um caminho de superação do que ela já foi atrelada ao passado, almejando, na atualidade, trazer contribuições significativas para a vida do praticante, mais especificamente para a vida dos estudantes nas escolas, pois esse conhecimento, que foi historicamente produzido, tem possibilidades de ser um conteúdo estruturante nas aulas de Educação Física com planejamento e aprendizagens durante as aulas, deixando de ser um instrumento para conduzir a outros conteúdos da Educação Física ou deixar de ser apenas um aquecimento corporal.

Porém, quando passamos para a pesquisa de campo, percebemos mais fortemente que a ação do professor está permeada por diversas problemáticas que dificultam a sua prática pedagógica e a sistematização do conhecimento. Como uma pesquisa participante e ainda subsidiada pelos estudos da hermenêutica-dialética, por meio do acompanhamento sistemático das aulas da unidade do conteúdo Ginástica, conseguimos perceber os avanços do conhecimento de um ano para outro. Cada ano possui sua particularidade e o professor demonstrou que conseguia lidar com cada um deles, apresentando aulas que conseguiam envolver os estudantes e incentivar os mesmos a aprender, proporcionando diferentes propostas de aulas para cada ano.

Refletimos, então, que a Ginástica como conhecimento histórico, quando se apresenta como conteúdo da Educação Física, precisa possuir diversas peculiaridades para se sustentar como um conhecimento possível de ser sistematizado. A Ginástica precisa contribuir com a reflexão pedagógica dos estudantes, e não ser um conhecimento desprovido de formação humana, pois é necessário elevar o pensamento teórico nos estudantes.

Portanto, constatamos que no contexto das Escolas de Referência em Ensino Médio existe uma preocupação 
com o ensino-aprendizagem sistematizado e que a Ginástica é um dos conteúdos que os professores almejam sistematizar. Apesar de todas as dificuldades, identificamos que existem possibilidades da sua prática ocorrer de forma sistematizada, pois foi possível perceber isso nas observações das aulas realizadas, nas quais aspectos relacionados a capacidades e, principalmente, a habilidades constituíram-se como pontos-chave para ocorrer a sistematização.

\section{FINANCIAMENTO}

All Agencies: Coordenação de Aperfeiçoamento de Pessoal de Nível Superior, (Grant / Award Number: '1').

\section{CONFLITOS DE INTERESSE}

Declaramos não existir nenhum conflito de interesse, incluindo interesses pessoais, políticos, comerciais, acadêmicos ou financeiros. Declaramos ainda que o apoio financeiro para o desenvolvimento deste trabalho está claramente informado no texto.

\section{REFERÊNCIAS}

Almeida RS. A Ginástica na escola e na formação de Professores [tese]. Salvador: Faculdade de Educação, Universidade Federal da Bahia; 2005.

Bardin L. Análise de conteúdo. São Paulo: Edições 70; 2011.

Bezerra LA, Farias GO, Folle A, Bezerra J. Ginástica na Formação inicial em Educação Física: análise das produções científicas. Rev. Educ. Fís/UEM 2014;25(4):663-73. http:// dx.doi.org/10.4025/reveducfis.v25i4.22689.

Coletivo de Autores. Metodologia do Ensino de Educação Física. São Paulo: Cortez; 1992.

Costa RM. A Ginástica na escola. Uma perspectiva pedagógica na Educação Física. EFDeportes.com 2016;20(214).

Dutra PFV. Educação integral no estado de Pernambuco: uma política pública para o Ensino Médio. Recife: UFPE; 2014.
Lara LM, Rinaldi IPB, Montenegro J, Seron TD. Dança e ginástica nas abordagens metodológicas da Educação Física Escolar. Rev Bras Ciênc Esporte 2007;28:155-70.

Lorenzini AR. Conteúdo e método da educação física escolar: contribuições da Pedagogia Histórico-Crítica e da Metodologia Crítico-Superadora no trato com a ginástica [tese]. Salvador: Faculdade de Educação, Universidade Federal da Bahia; 2013.

Minayo MCS. O desafio do conhecimento: pesquisa qualitativa em saúde. Rio de Janeiro: Abrasco; 2010.

Pernambuco. Governo do Estado. Secretaria de Educação. Proposta Curricular para o Ensino Médio Integral Linguagens e códigos e suas tecnologias. Recife: Governo do Estado de Pernambuco; 2012.

Pernambuco. Secretária de Educação de Pernambuco. Parâmetros Curriculares para a Educação Básica do Estado de Pernambuco: Parâmetros Curriculares de Educação Física - Ensino Fundamental e Médio. Recife: Secretária de Educação de Pernambuco; 2013a.

Pernambuco. Secretária de Educação de Pernambuco. Parâmetros para a Educação Básica do Estado de Pernambuco: Parâmetros na sala de aula - Educação Física Ensino Fundamental e Médio. Recife: Secretária de Educação de Pernambuco; 2013b.

Sacristán JGO. Currículo - uma reflexão sobre a prática. 3. ed. Porto Alegre: Artmed; 2000.

Sampieri RH, Colado CF, Lucio MPB. Metodologia da pesquisa. São Paulo: McGraw-Hill; 2013.

Schiavon L, Piccolo VN. A Ginástica vai à Escola. Movimento (Porto Alegre). 2007;13(03):131-50. http://dx.doi. org/10.22456/1982-8918.3572.

Silva AS, Pinto JM. Metodologia das ciências sociais. Porto: Afrontamento; 2003.

Strauss C. Ginástica: a arte do movimento. São Paulo: Hemus; 1977. p. 7-15.

Triviños ANS. Introdução à Pesquisa em Ciências Sociais: a pesquisa qualitativa em educação. São Paulo: Atlas; 2010. 